JNOTEP 5 (1) Oktober (2018): 31-37

JINOTEP (Jurnal Inovasi Teknologi Pembelajaran)

Kajian dan Riset Dalam Teknologi Pembelajaran

http://journal2.um.ac.id/index.php/jinotep/index

\title{
KONSEP DAN PENERAPAN PENDIDIKAN SEPANJANG HAYAT DALAM KELUARGA
}

\author{
Muhammad Yunus ${ }^{1}$, Agus Wedi \\ ${ }^{1}$ Universitas Syiah Kuala-Banda Aceh, ${ }^{2}$ Universitas Negeri Malang \\ yunus.msalem@unsyiah.ac.id
}

\section{Article History}

Received: Oct 09, 2018

Accepted: March 22, 2019

Published:March 23, 2019

\section{Keywords}

Konsep,Penerapan, Pendidikan Sepanjang Hayat, Keluarga

\begin{abstract}
Abstrak
Tujuan penulisan ini adalah untuk: 1) menemukan pengertian pendidikan sepanjang hayat dalam keluarga. 2) menemukan konsep dan pola penerapan pendidikan sepanjang hayat dalam keluarga. Penggaliah referensi yang ada menjadi metode untuk mendapatkan sejumlah bahan dan konsep yang dilakukan terhadap sejumlah buku dan artikel yang terkait dengan tema yang akan di tuliskan. Hasil yang didapatkan sebagai berikut; 1) Pendidikan sepanjang hayat dalam keluarga adalah pendidikan yang diperoleh setiap anggota keluarga dalam keluarganya berupa pengetahuan, sikap maupun keterampilan sebagai bekal kehidupannya 2). Penarapan pendidikan sepanjang hayat dalam keluarga adalah upaya keluarga dalam memberikan pendidikan kepada anggota kelarga sepanjang hayatnya. 3) Pola penerapan pendidikan sepanjang hayat dalam keluarga meliputi: penanaman konsep tentang; tujuan hidup, respon terhadap keinginan, mengatasi problem yang dihadapi anak dengan cara yang logis, merencanakan kegiatan pendidikan dengan baik, serta mengarahkan dan menjelaskan pentingya pendidikan untuk kehipdupan anak.
\end{abstract}

\section{Abstract}

The purpose of this paper is to: 1) find an understanding of lifelong education in the family. 2) find concepts and patterns for the application of lifelong education in the family. The existing reference diggers are a method to get a number of materials and concepts carried out on a number of books and articles related to the theme that will be written. The results obtained are as follows; 1) Lifelong education in the family is education that is obtained by each family member in his family in the form of knowledge, attitudes and skills as a provision for his life 2). The hope of lifelong education in the family is the family's efforts in providing education to the members of the family throughout its lifetime. 3) The pattern of the application of lifelong education in the family includes: the planting of concepts about; life goals, responses to desires, overcoming problems faced by children in a logical way, planning education activities well, and directing and explaining the importance of education for children's lives.
Corresponding author :

Muhammad Yunus

Universitas Syiah Kuala-Banda Aceh

yunus.msalem@unsyiah.ac.id
2018 Universitas Negeri Malang p-ISSN 2406-8780 e-ISSN 2654-7953 
Konsep pendidikan sepanjang hayat (life long education) juga dikenal dengan konsep pembelajaran sepanjang hayat (Life Long Learning). Life long leaning juga sering disebut dengan istilah belajar sepanjang hayat. Perkembangan konsep ini sekitar tahun 1970-an yang menjadi penekanannya adalah menggunakan istilah lifelong learning pada istilah belajar sepanjang hayat. Gustavssen 1995, Boshier 1998 dikutip kembali oleh John Field (2001) menjelaskan bahwa pada tahun 1960-an dan 1970-an, belajar seumur hidup sebagai konsep adalah humanistik dan bahkan radikal, tetapi sejak itu 1990-an telah menjadi semakin ekonomis dan konservatif dalam implikasinya. Sedangkan David N. Aspin, Judith. Chapman (2000) menjelaskan bahwa istilah 'belajar seumur hidup digunakan dalam berbagai konteks yang luas dan memiliki cakupan yang luas, sehingga sering tidak jelas. Mungkin karena alasan itu operasionalisasi dan implementasi belum banyak dilakukan.

Konsep belajar sepanjang hayat, pembelajaran sepanjang hayat, dan kemudian menjadi pendidikan sepanjang hayat merupakan konsep yang sama. Perbedaannya hanya pada konteks dimana kegiatan tersebut berlansung dan sangat dipengaruhi oleh lingkungan dimana orangorang belajar. Ridhwan Nasir, (2005) menjelaskan bahwa pendidikan sepanjang hayat (Life Long Education) merupakan azas yang dirumuskan bahwa proses pendidikan merupakan suatu proses kontinyu, yang bermula sejak seseorang dilahirkan hingga meninggal dunia. Proses pendidikan ini mencakup bentuk-bentuk belajar secara informal, formal, dan non formal baik yang berlangsug dalam keluarga, sekolah, maupun dalam kehidupan masyarakat.

Hasbullah, (2008) Menuliskan empat konsep kunci Pendidikan Sepanjang Hayat (Life Long Education) yaitu:

1. Konsep Pendidikan Sepanjang Hayat (Life Long Education) sebagai suatu konsep, yang diartikan sebagai tujuan atau ide formal untuk pengorganisasian dan penstrukturan pengalamanpengalaman pendidikan.

2. Konsep belajar sepanjang hayat; berarti pebelajar belajar karena respon terhadap keinginan yang didasari untuk belajar dan angan-angan pendididkan menyediakan kondisi-kondisi yang membantu belajar.

3. Konsep pebelajar sepanjang hayat; pebelajar seumur hidup dimaksudkan adalah orang-orang yang sadar tentang diri mereka sebagai pebelajar seumur hidup. Melihat belajar baru sebagai cara yang logis untuk mengatasi problema dan terdorong tinggi sekali untuk belajar diseluruh tingkat usia dan menerima tantangan dan perubahan seumur hidup sebagai pemberi kesempatan untuk belajar baru.

4. Kurikulum Pendidikan Sepanjang Hayat (Life Long Education); kurikulum dalam hubungan ini didesain atas dasar prinsip pendidikan sepanjang hayat (Life Long Education) betul-betul telah menghasilkan pelajar seumur hidup yang secara berurutan melaksanakan belajar seumur hidup.

Fathul Jannah (2013) menjelsakan pendidikan seumur hidup adalah sistem pendidikan yang menerangkan keseluruhan peristiwa kegiatan belajar mengajar dalam keseluruhan kehidupan manusia. Proses pendidikan seumur hidup berlangsung secara kontinyu dan tidak terbatas oleh waktu, dan tempat sepanjang perjalanan hidup manusia sejak lahir hingga meninggal dunia baik secara formal, in formal maupun non formal. Untuk lebih mendalamnya kajian dengan tema Pendidikan Sepanjang Hayat dalam Keluarga, maka tulisan ini bertujuan untuk; 1) Menjelaskan makna pendidikan sepanjang hayat dalam keluarga. 2) Menjeaskan makna penerapan pendidikan sepanjang hayat dalam keluarga. 3) Menjelakan strategi penerapan 
pendidikan sepanjang hayat dalam keluarga.

\section{Makna Pendidikan Sepanjang Hayat Dalam Keluarga}

\section{Makna Keluarga}

Sebelum dijelaskan lebih lanjut tentang konsep pendidikan sepanjang hayat dalam keluarga, terlebih dahulu menjelaskan batasan keluarga yang dimaksud dalam tulisan ini. Ki Hadjar Dewantara dalam (Neni Yohana; 2017) menjelaskan bahwa keluarga adalah suatu kumpulan beberapa orang yang karena terikat oleh satu turunan lalu mengerti dan berdiri sebagai satu gabungan yang hak, dan berkehendak bersama-sama memperteguh gabungan itu untuk kemuliaan semua anggotanya. Konep keluarga alam aspek paedagogis adalah satu persekutuan hidup yang dijalin kasih sayang antara pasangan dua jenis manusia yang dikukuhkan dengan pernikahan dengan maksud untuk saling menyempurnakan (Berns, 2007).

Dari konsep-konsep di atas dapat dipahami bahwa dalam keluarga terdapat dua atau lebih dari dua pribadi yang tergabung karena hubungan darah, hubungan perkawinan atau pengangkatan, hidupnya dalam satu rumah tangga, berinteraksi satu sama lain dan didalamnya terdapat peran masing-masing dan menciptakan serta mempertahankan tujuan hidup bekeluarga. Berdasarkan pemahaman tersebut penulis memberikan definisi bahwa keluarga adalah kelompok social yang terdiri dari ayah, ibu dan anak, dimana bubungan social diantara anggota keluarga tersebut relatif tetap dan didasarkan atas ikatan perkawinan, darah yang memiliki dan dijiwai rasa kasih sayang dan tanggung jawab bersama.

\section{Pengertian Pendidikan dalam Keluarga}

Dalam UU RI No. 20 Tahun 2003 tentang Sistem Pendidikan Nasional, Pasal 1 menyebutkan bahwa "pendidikan adalah usaha sadar dan terencana untuk mewujudkan suasana belajar dan proses pembelajaran agar peserta didik secara aktif mengembangkan potensi dirinya untuk memiliki kekuatan spiritual keagamaan, pengendalian diri, kepribadian, kecerdasan, akhlak mulia, serta keterampilan yang diperlukan dirinya, masyarakat, bangsa, dan negara. Pasal 27 ayat 1 UU R.I. No. 20 Tahun 2003 yang tertulisakn bahwa "kegiatan pendidikan informal yang dilakukan oleh keluarga dan lingkungan berbentuk kegiatan belajar secara mandiri".

Durkheim dalam Ardiwinata (2008) menjelaskan bahwa pendidikan merupakan sebuah fakta sosial karena mengandung cirri-ciri: (1) berada di luar individu dan bersifat langgeng, artinya telah ada sebelum individu lahir dan akan tetap ada meskipun individu berpulang ke asalnya, (2) memiliki daya paksa terhadap individu untuk melakukan dan menjalaninya, (3) tersebar di warga masyarakat dan menjadi milik warga masyarakat. Seangkan Mansur (2005 mendefiniskan pendidikan keluarga adalah proses pemberian positif bagi tumbuh kembangnya anak sebagai pondasi pendidikan selanjutnya. An-Nahlawi dalam Hasan Langgulung (1986) menjelaskan bahwa pendidikan keluarga adalah usaha yang dilakukan oleh ayah dan ibu sebagai orang yang diberi tanggung jawab untuk memberikan nilai-nilai, akhlak, keteladanan dan kefitrahan.

Berdasarkan pengertian di atas dapat dipahami bahwa pendidikan keluarga selalu terlihat dalam keseharian anak yang berinteraksi dengan anggota keluarganya. Terutama interaksi anak dengan ayah, ibu, kakak dan adiknya. Pendidikan dalam keluarga juga terlihat pada hasil belajar yang bersifat lansung dan dalam wujudnya jangka pendek. Namun tidak sedikit pendidikan dalam keluarga juga merancang dalam tujuan jangka panjang bagi tujuan pendidikan anaknya. Dengan proses dan pola pendidikan dalam keluarga yang selalu berinteraksi berupa proses belajar dan berlangsung secara terus menerus sepanjang hayat manusia. 
34 JINOTEP (Jurnal Inovasi dan Teknologi Pembelajaran) Kajian dan Riset dalam Teknologi Pembelajaran Vol. 5, No. 1, Oktober 2018, Hal. 31-37

\section{Makna Pendidikan Sepanjang Hayat Dalam Keluarga}

Dari berbagai referensi yang sudah coba digali, belum didapatkan definisi operasionali pendidikan sepanjang hayat dalam keluarga. Maka dalam hal ini penulis mencoba memaparkan konsep-konsep yang berkaitan dengan makna pendidikan sepanjang hayat dalam keluarga. Dengan memaparkan konsep konsep tersebut barangkali akan dapat melahirkan suatu konsep atau definis mengenai pendidikan sepanjang hayat dalam keluarga. M. Noor Syam, (1998), menjelaskan bahwa pendidikan seumur hidup merupakan konsep pendidikan yang menerangkan tentang keseluruhan peristiwa kegiatan belajar mengajar dalam proses pembinaan kepribadian yang berlangsung secara kontinyu dalam keseluruhan hidup manusia. Pandangan lain dikemukakan oleh Halsey, dalam Gorard (1999), keluarga secara universal diakui sebagai penentu utama kinerja pendidikan di sekolah baik sekolah dasar dan menengah dan, juga pendidikan tinggi. Sedangkan Mudyahardjo, R., (2003), pendidikan seumur hidup, yang disebut dengan Life Long Education adalah pendidikan yang menekankan bahwa proses pendidikan berlangsung terus menerus sejak seseorang dilahirkan hingga meningal dunia, baik dilaksanakan di jalur pendidikan sekolah, masyarakat maupun keluarga

Konsep yang dikemukakan di atas, memperlihatkan bahwa pendidikan sepanjang hayat merupakan kegiatan belajar dalam keseluruhan hidup manusia. Artinya dimanapun manusia itu berada mereka akan terus belajar baik di lembaga formal, non formal maupun dalam kehidupan keluarga. Oleh karena itu pendidikan sepanjang hayat dapat dilakukan dalam keluarga, sekolah maupun masyarakat. Berdasarkan tujuan tulisan ini, maka penulis mencoba memberikan definisi operasional tentang pendidikan sepanjang hayat dalam keluarga. Dengan keterbatsan penulis, maka penulis mengatakan bahwa pendidikan sepanjang hayat dalam keluarga adalah pendidikan yang diperoleh setiap anggota keluarga sebagai hasil dari proses belajar, baik secara langsung maupun tidak langsung dimana hasilnya dapat berupa pengetahuan, sikap maupun keterampilan yang dapat bertahan selama kehidupannya.

\section{Makna Penerapan Pendidikan Sepanjang Hayat Dalam Keluarga}

Walaupun definisi baku tentang penerapan pendidikan sepanjang hayat dalam keluarga belum ditemukan, berikut ini dipaparkan beberapa referensi yang mendukung perumusan definisi konsep sesuai tujuan tulisan ini. Salah satu teori yang berkenaan dengan penerapan pendidikan anak dalam keluarga adalah teori tabularasa John Locke dan Francis Bacon dalam (Suhar AM; 2009). Teori ini mengatakan bahwa anak yang baru dilahirkan itu dapat diumpamakan sebagai kertas putih yang belum ditulisi apapun (a sheet ot white paper avoid of all characters). Akal itu seperti kertas putih, berbagai ide yang terdapat di dalam benak manusia berasal dari pengalaman manusia itu sendiri. Dalam hal ini salah satu yang paling dekat dengan anak yang dilahirkan adalah orang tua atau keluarganya, oleh karena itu pendidikan pertama yang akan memberikan warna pada kehidupan anak sehingga berkembang menjadi luar biasa adalah pendidikan dalam keluarga.

Pandangan yang jelas-jelas mengungkapkan tentang penerapan pendidikan sepanjang hayat dalam keluarga adalah terlihat dalam konsep pendidikan Islam. Nabi Muhammad SAW. (571-633 M) telah mengungkapkan bahwa "tiada seorang anakpun yang lahir kecuali ia dilahirkan dalam keadaan fitrah, maka kedua orang tuanyalah yang menjadikan ia Yahudi, Nasrani dan Majusi"(Amir D.I; 1973). Dalam hadis yang lain yang dikutip oleh Wawan Wahyuddin (2016) menuliskan Rasulullah SAW bersabda 
"Tuntutlah ilmu sejak dari buaian sampai liang lahat". Sehingga salah satu kesimpulan tulisan beliau yaitu; Agama Islam mewajibkan umatnya untuk menuntut ilmu pengetahuan bagi setiap insan, sejak lahir hingga meninggal dunia.

Pendapat yang lebih mengarah pada definisi tentang pendidikan sepanjang hayat dalam keluarga dikemukakan oleh Amir Daien Indrakusuma, (1973) yaitu; pendidikan sepanjang hayat (Life Long Education) dalam lingkungan keluarga merupakan tempat belajar yang pertama bagi seorang manusia. Lingkungan keluarga, pada tahap inilah yang paling menentukan seorang anak untuk memulai pembelajaran dalam keluarganya. Tugas utama dari keluarga bagi pendidikan anak ialah sebagai peletak dasar bagi pendidikan akhlak dan pandangan hidup keagamaan. Sifat dan tabiat anak sebagian besar diambil dari kedua orang tuanya dan dari anggota keluarga yang lain.

Berdasarkan konsep-konsep di atas, dapat dipahami bahwa belum ditemukan definisi operasional tentang penerapan pendidikan sepanjang hayat dalam keluarga, namun gambaran adanya penerapan pendidikan sepanjang hayat dalam keluarga sudah sangat jelas. Dikarenakan belum ditemuan referensi yang mendukung tentang pengertian penerapan pendidikan sepanjang hayat dalam keluarga, maka penulis mencoba memberikan definisi sesuai dengan maksud dalam tulisan ini. Penerapan pendidikan sepanjang hayat dalam keluarga adalah upaya keluarga dalam memberikan pendidikan berkenaan dengan sejumlah pengetahuan, keterampilan dan sikap sebagai pondasi untuk keberlangsungan hidup sepanjang hayat bagi anak-anak atau anggota keluarganya.

\section{Pola Penerapan Pendidikan Sepanjang Hayat Dalam Keluarga}

Sebagaimana pengertian penerapan pendidikan sepanjang hayat dalam keluarga yang telah dikemukakan sebelumnya, maka penerapan yang dipaparkan dalam hal ini adalah pola-pola penerapan strategi pendidikan sepanjang hayat dalam keluarga. Pola-pola strategi penerapan pendidikan dengan memaparkan contoh contoh penerapan pendidikan sepanjang hayat dalam keluarga. Soelaiman Joesoef (2002) dalam Fathul Jannah (2013), menjelaskan bahwa strategi penerapan pendidikan seumur hidup meliputi: a) penanaman konsep dasar pendidikan seumur hidup yaitu: menanamkan tujuan, merespon terhadap keinginan, menjelaskan cara yang logis untuk mengatasi problem, dan merancang dalam kurikulum. b) mengarahkan dengan jelas tentang pendidikan anak dalam rangka menjalankan pendidikan seumur hidupnya.

Lebih lanjut Fathul Jannah (2013 menjelaskan pendidikan seumur hidup dalam rangka menambah pengetahuan dan keterampilan yang dibutuhkan dan diarahkan pada: 1) Anak-anak, yaitu pendidikan bagi anak dengan program kegiatan tersusun mulai dari peningkatan kecakapan baca tulis, keterampilan dasar, mempertinggi daya pikir, sehingga membuat anak belajar berpikir kritis dan mempunyai pandangan hidup ke depan. 2) Orang dewasa, yaitu sebagai generasi penerus, kaum muda/dewasa membutuhkan pendidikan seumur hidup dalam rangka pemenuhan "self interest" yang merupakan tuntutan hidup sepanjang hayat.

Berdasarkan referensi di atas dapat dipahami bahwa pendidikan dalam keluarga yang terfokus pada anak-anak dan orang dewasa yang jadi fokus tulisan ini menggunakan istilah pola strategi penerapan pendidikan sepanjang hayat dalam keluarga dengan memaparkan contoh-contohnya. Contoh contoh yang dipaparkan ini merupakan hasil pengalaman yang didapatkan dalam keluarga yang dihubungkan dengan prinsip-prinsip dan konten pendidikan sepanjang hayat dalam kehidupan keluarga. Penjelasan mengenai contoh penerapan pendidikan sepanjang hayat dalam keluarga dalam tulisan ini hanya difokuskan pada: contoh yang berhubungan dengan keyakinan, contoh 
36 JINOTEP (Jurnal Inovasi dan Teknologi Pembelajaran) Kajian dan Riset dalam Teknologi Pembelajaran Vol. 5, No. 1, Oktober 2018, Hal. 31-37

yang berhubungan dengan pembentukan karakter, dan contoh yang berhubungan dengan pembentukan kepribadian sosial.

1) Contoh yang berhubungan dengan keyakinan, yaitu penanaman tentang ketauhidan pada anak, ketika bertanya tentang wujud Tuhan, jaaban harus disuaikan dengan tingkat usia anak.

2) Contoh yang berhubungan dengan pembentukan karakter, yaitu perilaku santun, menghargai, menghomati dan lainnya harus ditunjukkan orang tua kepada anaknya, hal itu disebabkan anak akan secara umum akan mengikuti kebiasaan orang tuanya.

3) Contoh yang berhubungan dengan pembentukan kepribadian sosial, yaitu . dalam hal ini orang tua harus memberikan pengarahan penjelasan kepedulian, bekerjasam, gotong royong dan lainlain, sehingga karakter yang ada hubungannya dengan nilai-nilai sosial dan budaya ini dapat menjadi kepribadiannya dalam kehidupan bermasyarakat.

Berdasarkan referensi ang ada, serta pemaparan contoh-contoh dalam kehidupan, maka pola strategi yang digunakan untuk penerapan pendidikan sepanjang hayat dalam keluarga diupayakan dengan pola asuh yang sesuai dengan tuntutan esensi hidup manusia yang dapat dibenarkan secara nilai nilai kemanusian. Diantara pola asuh tersebut menurut pemikiran penulis yaitu: 1) pola asuh yang dapat menguatkan kepribadian anak dengan karakter tangguh, disiplin, ulet, pekerja keras, berani dan pantang menyerah. 2) pola asuh demokratis agar anak tumbuh kepribadian kepekaan terhadap lingkungan seperti berempati, menhargai, toleransi, bekerjasama, gotong royong dan berkolaborasi. 3) pola asuh keteladanan dan bimbingan, dimana orang dewasa berkewwajiban memberikan keteladanan kepada anggota keluarga dan terus membimbing serta mengarahkan agar anak tumbuh dan berkembang dengan keperibadian sejati sesuai dengan harapan keluarga, agama dan bangsa.

Berdasarkan pembahasan yang telah dikemukan di bagian sebelumnya, maka dapat disimpulkan berikut: Pendidikan sepanjang hayat dalam keluarga adalah pendidikan yang diperoleh setiap anggota keluarga sebagai hasil dari proses belajar baik secara langsung maupun tidak langsung dimana hasilnya dapat berupa pengetahuan, sikap maupun keterampilan yang dapat bertahan selama kehidupannya. Penarapan pendidikan sepanjang hayat dalam keluarga adalah upaya keluarga dalam memberikan pendidikan berkenaan dengan sejumlah pengetahuan, keterampilan dan sikap sebagai pondasi untuk keberlangsungan hidup sepanjang hayat bagi anak-anak atau anggota keluarganya. Pola pola strategi penerapan pendidikan sepanjang hayat dalam keluarga meliputi: penanamkan konsep tentang; tujuan hidup, respon terhadap keinginan, mengatasi problem yang dihadapi anak dengan cara yang logis, merencanakan kegiatan pendidikan dengan baik, serta mengarahkan dan menjelaskan pentingya pendidikan untuk kehipdupan anak.

\section{KETERBATASAN}

Berdasarkan bahasan dan simpulan yang telah dikemukakan dibagian sebelumnya, maka penulis menyarankan agar penulis lain dapat memaparkan teori atau hasil penelitian yang lebih terfokus pada penerapan pendidikan sepanjang hayat dalam keluarga. Keterbatasan tulisan ini adalah, penulis belum mampu menemukan teori atau hasil penelitian yang betul betul sesuai dengan tema yang sedang ditulis. Penulis menyadari keterbatasan penulis dalam menemukan sejumlah teori atau hasil penelitian yang berkaitan tema ini, sehingga memungkinkan disempurnakan oleh penulis lainnya 


\section{DAFTAR RUJUKAN}

Aspin, D. N., \& Chapman, J. D. (2007). Lifelong learning: Concepts and conceptions. In Philosophical perspectives on lifelong learning (pp. 19-38). Springer, Dordrecht.

Berns, \& Roberta, M., 2007, Child, Family, School, Community Socilization and Support. United State: Thomson Corporation

Field, J., 2001, Lifelong Education, International Journal of Lifelong Education: Vol.20: No.2, 3-15

Gorard, S., Rees, G., \& Fevre, R. (1999). Patterns of participation in lifelong learning: Do families make a difference?. British educational research journal, 25(4), 517532.

Hasbullah, 2008, Dasar-Dasar Ilmu Pendidikan, Jakarta: PT. Raja Grafindo Persada.

Indrakusuma, A.D., 1973, Pengantar Ilmu Pendidikan, Surabaya: Usaha Nasional.

Jajat, A.S., \& Hufad, A., 2008. Sosiologi dan Antropologi Pendidikan. Bandung : UPI PRESS

Jannah, F. (2013). Pendidikan Seumur Hidup dan Implikasinya. Dinamika Ilmu: Jurnal Pendidikan, 13(1).
Langgulung, H., (1986) Manusia dan Pendidikan, Jakarta : Al-Husna.

Mansur, 2005, Pendidikan Anak Usia Dini dalam Islam. Yogyakarta : Pustaka Pelajar

Mudyahardjo, R., 2003, Pengantar Pendidikan: Jakarta, Rajagrafindo Persada

Nasir, R., 2005, Mencari Tipologi Format Pendidikan Ideal, Yogyakarta: Pustaka Pelajar.

Suhar, A.M., 2009, Filsafat Umum : Konsep, Sejarah dan Aliran, Gaung Persada Press, Jakarta.

Syam, M. N., 1998. Pengantar Dasar-Dasar Pendidikan; Jakarta, Usaha Nasiona

Undang-Undang Republik Indonesia No. 20 Tahun 2003, Sistem Pendidikan Nasional: Depdiknas, Jakarta

Wahyuddin, W. (2017). Pendidikan sepanjang hayat menurut perspektif islam. Saintifika Islamica: Jurnal Kajian Keislaman, 3(02), 191-208.

Yohana, N. (2017). Konsepsi pendidikan dalam keluarga menurut pemikiran $\mathrm{Ki}$ Hadjar Dewantara dan Hasan Langgulung. OASIS: Jurnal Ilmiah Kajian Islam, 1(2), 126-145. 